\title{
Detrimental effects of heat stress on grain weight and quality in rice (Oryza sativa L.) are aggravated by decreased relative humidity
}

\author{
Haoliang Yan ${ }^{1}$, Chunhu Wang ${ }^{1}$, Ke Liu ${ }^{1}$, Xiaohai Tian ${ }^{\text {Corresp. } 1}$ \\ ${ }^{1}$ Hubei Collaborative Innovation Center for Grain Industry/College of Agriculture, Yangtze University, Jingzhou Hubei, China \\ Corresponding Author: Xiaohai Tian \\ Email address: xiaohait@sina.com
}

There is concern over the impact of global warming on rice production due increased heat stress, coupled with decreased relative humidity $(\mathrm{RH})$. It is unknown how rice yield and quality are affected by heat stress and decreased $\mathrm{RH}$ during the grain filling stage. We conducted experiments in controlled growth chambers on six rice cultivars, varying in heat tolerance using 12 combinative treatments of three factors: two RH levels ( $75 \%$ and $85 \%$ ), three temperature levels (the daily maximum temperature at $33^{\circ} \mathrm{C}, 35^{\circ} \mathrm{C}$, and $37^{\circ} \mathrm{C}$ ), and two durations ( $8 \mathrm{~d}$ and $15 \mathrm{~d}$ after anthesis). Results showed that RH75\% with temperature treatments significantly reduced grain weight, which was higher than RH85\% . The same trend was also observed for both head rice rate and chalkiness. R168 was the most heattolerant cultivar, but it still had some differences in grain weight, head rice rate, and chalkiness between the two RH regimes. The lower $\mathrm{RH}$ was most detrimental at $35^{\circ} \mathrm{C}$, and to a lesser extent at $33^{\circ} \mathrm{C}$, but had a negligible effect at $37^{\circ} \mathrm{C}$. Our results provide a better understanding of temperature and $\mathrm{RH}^{\prime} \mathrm{s}$ interaction effects on rice quality during the grain filling stage, suggesting that $\mathrm{RH}$ should be considered in heat tolerance screening and identification to facilitate rice breeding and genetic improvement. 


\section{Detrimental effects of heat stress on grain weight and}

2 quality in rice (Oryza sativa L.) are aggravated by

\section{3 decreased relative humidity}

4

5

6 Haoliang Yan, Chunhu Wang, Ke Liu, Xiaohai Tian

7

8 Hubei Collaborative Innovation Center for Grain Industry/College of Agriculture, Yangtze

9 University, Jingzhou, Hubei 434025, China

10

11 Corresponding Author:

12 Xiaohai Tian

1388 Jingmi Rd, Jingzhou, Hubei, 434025, China

14 Email address: xiaohait@sina.com 


\section{Abstract}

17 There is concern over the impact of global warming on rice production due increased heat

18 stress, coupled with decreased relative humidity $(\mathrm{RH})$. It is unknown how rice yield and quality

19 are affected by heat stress and decreased RH during the grain filling stage. We conducted

20 experiments in controlled growth chambers on six rice cultivars, varying in heat tolerance

21 using 12 combinative treatments of three factors: two $\mathrm{RH}$ levels (75\% and 85\%), three

22 temperature levels (the daily maximum temperature at $33^{\circ} \mathrm{C}, 35^{\circ} \mathrm{C}$, and $37^{\circ} \mathrm{C}$ ), and two

23 durations ( $8 \mathrm{~d}$ and $15 \mathrm{~d}$ after anthesis). Results showed that $\mathrm{RH} 75 \%$ with temperature

24 treatments significantly reduced grain weight, which was higher than RH85\%. The same trend

25 was also observed for both head rice rate and chalkiness. R168 was the most heat-tolerant

26 cultivar, but it still had some differences in grain weight, head rice rate, and chalkiness between

27 the two RH regimes. The lower RH was most detrimental at $35^{\circ} \mathrm{C}$, and to a lesser extent at $2833^{\circ} \mathrm{C}$, but had a negligible effect at $37^{\circ} \mathrm{C}$. Our results provide a better understanding of 29 temperature and RH's interaction effects on rice quality during the grain filling stage, 30 suggesting that $\mathrm{RH}$ should be considered in heat tolerance screening and identification to 31 facilitate rice breeding and genetic improvement. 


\section{Introduction}

35 The average global surface temperature has risen by an estimated $0.85^{\circ} \mathrm{C}$ from $1880-2012$

36 (Stocker et al., 2013). Evaporation over land has increased because the rate of warming is

37 greater on land than in the sea. However, the limitations of soil moisture, water supply, and 38 crop transpiration cause a decrease in the near-surface relative humidity $(\mathrm{RH})$ over land. As a 39 result, most land types, except coastal areas, will become drier (Byrne \& O'Gorman, 2016; Dai 40 et al., 2018; Orimoloye et al., 2018; Po-Chedley et al., 2018).

41 Rice is one of the most important staple cereals, providing food for more than half of the 42 world's population (Seck et al., 2012). However, rice yields fluctuate considerably and are 43 44 susceptible to climate change (Jagadish et al., 2015; Yan et al., 2017). With each $1{ }^{\circ} \mathrm{C}$ increment in the whole-season minimum temperature, there is a $10 \%$ loss in yields (Peng et al., 2004). In addition to the detrimental effects of heat stress, heat can also damage the quality of the grain, leading to considerable economic losses (Lyman et al., 2013).

The grain filling stage is one of the most critical periods for rice yield and grain quality formation and is sensitive to environmental stress (Yoshida, 1981). High temperatures during this period result in an accelerated grain filling rate, a shortened grain filling duration, lowered grain weight, and/or deteriorated milling quality caused by increased amounts of chalky and fissured grains forced into maturity by higher temperatures (Ambardekar et al., 2011; Bao, 2019; Cooper et al., 2006; Zhou et al., 2019). The early and middle grain-filling periods are the most susceptible to heat stressors, especially during the first 15 days (Cooper et al., 2008; Cooper et al., 2006; Wu et al., 2016). It has been suggested that a temperature range of $25^{\circ} \mathrm{C}$ to $29^{\circ} \mathrm{C}$ is optimal for the first $15-20 \mathrm{~d}$ of the grain-filling stage, but it is subject to the response of different cultivars with their varietal tolerance (Abayawickrama et al., 2017; Morita et al., 2016; Wu et al., 2016).

Starch biosynthesis is inhibited at high temperatures in the developing grains (Yamakawa \& Hakata, 2010; Yamakawa et al., 2007), and many immature starch granules are found in the endosperm cells (Zakaria et al., 2002). Altered expressions of $\alpha$-amylase genes and increased enzymatic activity were detected, suggesting that starch was degraded under elevated temperatures (Hakata et al., 2012). Sucrose transport and metabolism in the phloem of the leaf, sheath, stem, and grains are also inhibited in a heat stress-susceptible cultivar in a heat-stressed environment when compared to a heat stress-tolerant cultivar (Tanamachi et al., 2016; Zhang et al., 2018a). Heat stress may cause a starch shortage, reduced grain weight, and poor quality. 
67 induced damage in grain yield. It is affected by high-temperature stress during the grain filling 68 stage. Physiologically, panicle development is influenced by air temperature and humidity 69 (Weerakoon et al., 2008). The lower RH conditions (RH15\%) in New South Wales, Australia 70 alleviated heat-induced damage in rice through transpiration cooling during the flowering stage 71 when compared with the humidity in Hubei, China (Matsui et al., 2014; Tian et al., 2010; 72 Yoshimoto et al., 2012). Hot and dry wind conditions can accelerate water loss in panicles and 73 increase the chalky grain rate during the grain filling stage (Hiroshi et al., 2012; Kang et al., 74 2003). Oya \& Yoshida (2008) found a clear difference in chalky formation among varieties 75 76 with wind treatments. It is not well understood how rice yield and quality are affected by heat stress coupled with different RH during the grain filling stage.

The endosperm cells of rice grains rely on osmotic adjustment to maintain cell turgor under heat stress (Wada et al., 2019), similar to rice grown under dry wind (Wada et al., 2014; Wada et al., 2011). This suggests a similar mechanism between the responses to high temperature and dry wind. A lower RH in the air also reduces head rice yield (F. Thompson \& G. Mutters, 2006). In northern India, RH showed a significant decline of $1.44 \%$ per year, which significantly affected the yield of most crops (Chakraborty \& Hazari, 2017). It is estimated that for every $1 \%$ decrease in average $\mathrm{RH}$ during the growing season in China, rice yield decreases by $0.75 \%$ (Zhang et al., 2017). These studies indicate that RH variation during the grain filling stage may impact rice yield and quality, but whether such a difference is aggravated in cultivars by the interaction of RH with temperature remains to be tested.

In the Jianghan basin of the middle Yangtze River Valley of Central China, mid-season indica rice varieties often suffer yield losses due to heat stress (Tian et al., 2010). Higher summer temperatures are always accompanied by decreased humidity (Gong et al., 2006; Guo et al., 2016). A maximum temperature of approximately $35^{\circ} \mathrm{C}$ or a daily mean temperature of $30^{\circ} \mathrm{C}$ lasting more than three days causes RH to decrease from $\sim 85 \%$ to $\sim 70 \%$ (Tian et al., 2010). Climate change has resulted in longer periods of higher temperatures in this region (Liu et al., 2019; Tan \& Shen, 2016). This study hypothesized that high temperatures, coupled with decreased RH, aggravate rice grain quality's adverse effects. We conducted experiments in a controlled environment with six rice cultivars varying in heat stress tolerance. We sought to determine: 1) the effect of RH on high temperature-induced grain weight and quality loss; 2) varietal differences under combinations of $\mathrm{RH}$ and temperature treatments. 
99 Materials \& Methods

100 Plant materials

101 Six rice cultivars with different heat tolerances at the grain filling stage were sourced from our

102 previous studies. They include three rice hybrids: Liangyou27 (LY27), Liangyou6 (LY6), and

103 Zhuliangyou47 (ZLY47), and three conventional varieties: 16343, R168, and IR64. R168 had

104 a smaller grain weight and quality difference between temperature conditions. IR64 and the

105 other four varieties showed sensitivity to high temperature (Table S1).

106

107 Growth conditions

108 A pot experiment was conducted in 2017 on Yangtze University experimental farm (Jingzhou

109 City, $112^{\circ} 09^{\prime} \mathrm{E}, 30^{\circ} 21^{\prime} \mathrm{N}, 32$ masl) in the western part of the Jianghan Basin in China.

110 Seeds were sown on April 8, 2017. 20-day-old seedlings were transplanted to each plastic pot

111 (inner diameter $30 \mathrm{~cm}$, height $30 \mathrm{~cm}$ ) containing $12.5 \mathrm{~kg}$ soil and $8 \mathrm{~g} \mathrm{~N}: \mathrm{P}: \mathrm{K}$ compound

112 fertilizer (26:10:15). After transplantation, the soil surface in the pots was kept submerged

113 until maturity in natural conditions. Tillers were cut off after they emerged, leaving only the

114 main stem in each plant throughout the entire growth period.

115

116 Treatment

117 Six controlled environments with a combined air temperature and relative humidity (RH) level

118 were simulated in a growth chamber (AGC-MR, Zhejiang Qiushi Environment Co., Ltd., 119 Zhejiang, China). Experimental treatments included two RH levels (i.e., RH75\% and RH85\%),

120 three temperature levels (daily maximum temperatures of $33^{\circ} \mathrm{C}, 35^{\circ} \mathrm{C}$, and $37^{\circ} \mathrm{C}$ ), and two

121 durations ( 8 and 15 days after anthesis) (Fig. 1). Hourly temperature changes were recorded

122 daily, and the results are shown in Fig. 1. The RH was kept constant in each treatment

123 environment.

124 Panicles heading on the same day were marked for treatments after anthesis. Six pots of each

125 cultivar were subjected to each combination of the controlled environment (temperature $\times \mathrm{RH}$

126 combinations) for eight and 15 days, respectively. The plants grown under natural conditions

127 (six pots per cultivar) were used as controls. Temperature and RH are shown in Table S2.

128

129 Measurements of grain weight, milling quality, and chalkiness

130 Filled grains were harvested and sun-dried to a moisture content of $13 \%$. We measured

131 thousand-grain weights with three replications. Samples were stored for three months (15- 
$13220^{\circ} \mathrm{C}$, RH: $10-20 \%$ ) and then the milling quality and chalkiness were measured. Rice grain 133 samples (30 g for each cultivar per treatment) were dehulled and polished for 30 seconds 134 (JDMZ100, Beijing Dongfu Jiuheng Instrument Technology Co., Ltd., China) to obtain milled 135 rice. The head rice was then separated and weighed. The weight of the head rice to the sample 136 weight $(30 \mathrm{~g})$ was calculated as the head rice rate. The chalkiness of the head rice was evaluated 137 with a rice appearance quality tester (JMWT12, Beijing Dongfu Jiuheng Instrument 138 Technology Co., Ltd., China).

139

\section{Stress tolerance estimation}

141 Stress tolerance was evaluated by the membership function value (MFV) based on the theory 142 of fuzzy mathematics (Zadeh, 1965). We used a method modified from Chen et al. (2012) and 143 Liu et al. (2015). The heat-tolerant coefficient (HC) was calculated as the ratio of the value in 144 the combinative treatment of temperature $\times \mathrm{RH} \times$ duration to that in the control of the same 145 cultivars for individual traits, using the following equation:

$$
\mathrm{HC}_{i j k}=\frac{\mathrm{X}_{i j k}}{\mathrm{CK}_{i j}}
$$

147 Where $\mathrm{HC}_{\mathrm{ijk}}$ is the heat-tolerant coefficient of the trait (i) for cultivar (j) in treatment $(\mathrm{k}), \mathrm{X}_{\mathrm{ijk}}$ 148 is the value of the trait (i) for the cultivar (j) in the treatment $(\mathrm{k}), \mathrm{CK}_{\mathrm{ij}}$ is the value of the trait 149 (i) for the cultivar (j) under the control condition.

150 As with HC, MFV for grain weight and head rice rate were calculated, using the following 151 equation:

$$
M F V_{i j k}=\frac{H C_{i j k}-\operatorname{Min}\left(H C_{i}\right)}{\operatorname{Max}\left(H C_{i}\right)-\operatorname{Min}\left(H C_{i}\right)}
$$

153 Where $\mathrm{MFV}_{\mathrm{ijk}}$ is the membership function value of heat tolerance of the trait (i) for the cultivar 154 (j) in treatment $(\mathrm{k}), \mathrm{HC}_{\mathrm{ijk}}$ is the same as earlier defined, $\mathrm{HC}_{\mathrm{i}}$ is the heat-tolerant coefficient 155 value of the trait (i) over all cultivars and all treatments.

156 The chalkiness value tends to increase after treatment, which is contrary to the changes in grain 157 weight and milled rice rate, and the absolute value of chalkiness under control conditions is 158 usually very small. The MFV for chalkiness was calculated using the following equation: 


$$
M F V_{i j k}=1-\frac{\mathrm{X}_{i j k}-\operatorname{Min}\left(\mathrm{X}_{i}\right)}{\operatorname{Max}\left(X_{i}\right)-\operatorname{Min}\left(X_{i}\right)}
$$

160 Where $\mathrm{X}_{\mathrm{i}}$ is the value of the trait (i) over all cultivars and all treatments.

161 For these three traits, MFVs are dimensionless, real number interval [0,1], standing for

162 individual cultivar's heat tolerance under treatments.

163

164 Data analysis

165 We used Microsoft Excel 2019 for data entry and collating and conducted the analysis of 166 variance (ANOVA) using the R package "agricolae" in R 3.6.0 to determine the effect of 167 treatment factors on grain weight and quality. We performed comparisons between treatment 168 means using the least significant difference test (LSD) at $P \leq 0.05$.

169 A full model was established via function "lm" in R package "stats" to evaluate the treatment 170 factors and their interactions on grain weight, head rice, and chalkiness. Then, a stepwise 171 backward selection based on the Akaike's information criterion (AIC) which performed with 172 function "stepAIC" in R package "MASS" in R 3.6.0 was used to find out the factors that 173 affected the grain weight, head rice rate, and chalkiness most (Venables et al. 2002). The 174 significance of each predictor was tested via a Student's t-test, all treatment factors and their 175 interactions left in the model were significant at the 0.01 level.

176 The full model of multiple linear regression as follow:

$$
Y=\beta_{1} X_{1}+\beta_{2} X_{2}+\beta_{3} X_{3}+\beta_{4} X_{4}+\beta_{12} X_{1} X_{2}+\beta_{13} X_{1} X_{3}+\beta_{23} X_{2} X_{3}+\beta_{123} X_{1} X_{2} X_{3}
$$

178 $+e$

Where $Y$ represents grain weight, head rice rate, and chalkiness in each treatment, respectively; $X_{1}$ represents the max daily temperature in each treatment; $X_{2}$ represents the relative humidity in each treatment; $X_{3}$ represents the treatment duration days in each treatment; and $X_{4}$ 182 represents the grain weight, head rice rate, and chalkiness of each cultivar under controlled 183 conditions to eliminate the differences in the variety; $\beta_{1}, \beta_{2}, \beta_{3}$, and $\beta_{4}$, are linear coefficients, 184 $\beta_{12}, \beta_{13}, \beta_{23}$, and $\beta_{123}$ represent interaction coefficients, with $e$ representing the intercept. 


\section{Results}

\section{Grain weight}

189 The effects of temperature, $\mathrm{RH}$, and temperature $\times \mathrm{RH}$ on grain weight were significant among

190 six cultivars (Table 1). The duration of treatment also had a significant effect on grain weight,

191 except for R168. Grain weight was significantly reduced in cultivars at RH 75\% coupled

192 temperature treatments, and the reduction was higher than that in RH 85\% over the same three

193 temperature treatments (Fig. 2). Under the same temperature and RH conditions, grain weight

194 significantly decreased from $8 \mathrm{~d}$ to $15 \mathrm{~d}$ of the duration treatment (Fig. 2). The impact of

195 different $\mathrm{RH}$ regime treatments (RH75\% vs. $\mathrm{RH} 85 \%$ ) on grain weight was smaller at $37^{\circ} \mathrm{C}$

196 than at $33^{\circ} \mathrm{C}$ and $35^{\circ} \mathrm{C}$ (Fig. 3).

197 Multiple regression analysis showed that grain weight decreased when temperature and

198 durations increased, which was the opposite effect when RH increased (Table 2).

199 MFVs of each trait displayed in Table 3 showed the heat tolerance of each cultivar under 200 treatments, with the mean value as a comprehensive index for the evaluation of heat stress 201 tolerance of each cultivar. R168 was found to have the highest mean MFV (0.70), followed by 202 IR64 (0.55), then LY27, LY6, ZLY47, and 16343 (0.54, 0.50, 0.45, and 0.44, respectively). 203 R168 also showed the smallest difference of MFVs between RH conditions. The treatment of $20435^{\circ} \mathrm{C}$ by $\mathrm{RH} 75 \%$ at 15 days showed the largest mean MFV difference among the cultivars and 205 could be used to evaluate high-temperature tolerance.

206 R168 and IR64 were also the two cultivars with the highest mean MFVs of grain weight and 207 the smallest difference between RH conditions (Table 3). Their grain weight decreased $>2 \mathrm{~g}$ 208 at $37^{\circ} \mathrm{C}$ (Fig 2). ZLY47 and 16343 showed high MFVs under temperatures of $33^{\circ} \mathrm{C}$ and their 209 grain weight decreased $>2 \mathrm{~g}$ at $35^{\circ} \mathrm{C}$ or $37^{\circ} \mathrm{C}$. LY27 and LY6 showed small MFVs at RH75\% 210 over temperature treatments, their grain weight decreased $>2 \mathrm{~g}$ at all three temperature 211 treatments.

212

\section{Head rice rate}

214 The head rice rate of all cultivars was significantly affected by temperature and RH (Table 1). 215 Durations also showed a significant detrimental effect on the head rice rate except in cultivar 216 ZLY47. Interactive effects of temperature $\times$ durations and $\mathrm{RH} \times$ durations were significant for 217 the head rice rate among cultivars, except LY6. The head rice rate significantly decreased in 218 cultivars at $\mathrm{RH} 75 \%$ over temperature treatments, and the reduction was higher than that at 219 RH85\% over the same temperature treatments when compared to the control (Fig. 4). The 
220 difference in head rice rate between the two $\mathrm{RH}$ treatments ( $\mathrm{RH} 75 \%$ vs. $\mathrm{RH} 85 \%$ ) was greatest 221 at $35^{\circ} \mathrm{C}$ and lowest at $37^{\circ} \mathrm{C}$ (Fig. 3), suggesting that $\mathrm{RH}$ has a pronounced effect on 222 temperature-induced head rice loss at $35^{\circ} \mathrm{C}$. A pronounced difference was found at $33^{\circ} \mathrm{C}$ only 223 in cultivars whose head rice rate was dramatically decreased (LY6 and ZLY47, Fig 4).

$224 \mathrm{R} 168$ was the most heat-tolerant in terms of head rice rate, except for the treatments of $37^{\circ} \mathrm{C}$ $225 \times$ RH 75\%, with an MFV of $>0.70$ (Table 3). In addition, R168 showed a stable and higher 226 head rice rate than other cultivars, even at $37^{\circ} \mathrm{C}$ (Fig 4). The MFVs of head rice rate for 16343 227 was $\geq 0.85$ at $33^{\circ} \mathrm{C}$ but dropped sharply at $35^{\circ} \mathrm{C}$ in both humidity treatments (Table 3 ). For 228 other cultivars, the temperature caused a sharp drop in response to RH. At RH $75 \%$ over 229 temperature treatments, the temperature was $33^{\circ} \mathrm{C}$ for LY6 and ZLY47, or $35^{\circ} \mathrm{C}$ for LY27; 230 under RH85\%, the temperature was $35^{\circ} \mathrm{C}$ for LY6 and ZLY47, or $37^{\circ} \mathrm{C}$ for LY27.

\section{Chalkiness}

233 For all cultivars, the temperatures, $\mathrm{RH}$, and the interaction of temperature $\times \mathrm{RH}$ had a 234 significant effect on chalkiness (Table 1). The treatment durations had a significant effect on 235 chalkiness for cultivars except 16343. The majority of cultivars had higher levels of chalkiness 236 at $\mathrm{RH} 75 \%$ than at $\mathrm{RH} 85 \%$, even with the same temperature and duration treatment (Fig. 5). 237 The difference in chalkiness between RH treatments (RH75\% vs. RH85\%) was most 238 pronounced at $35^{\circ} \mathrm{C}$, followed by $33^{\circ} \mathrm{C}$ (Fig. 3). However, the difference was the smallest at $23937^{\circ} \mathrm{C}$. Multiple regression analysis showed that chalkiness was higher when the temperature 240 or durations increased (Table 2).

241 R168 and IR64 showed the highest MFVs of chalkiness in all treatments (Table 3). R168 also 242 showed the smallest chalkiness difference between RHs (Fig 5). Compared to the control, the 243 chalkiness of R168 sharply increased (more than $10 \%$ ) only at $37^{\circ} \mathrm{C}$ by the RH treatments; this 244 was the case for IR64 at $35^{\circ} \mathrm{C}$ and $37^{\circ} \mathrm{C}$, or for the remaining cultivars at all three temperature 245 treatments (Fig 5). 


\section{Discussion}

247 An upward trend of long-term high-temperature stress coupled with decreased RH during rice 248 grain filling in the Yangtze River basin may occur due to climate change (Guan et al., 2015; 249 Tan \& Shen, 2016; Zhang et al., 2018b). Although some studies have shown that hot, dry winds 250 resulted in lower rice yield and a quality loss (Hiroshi et al., 2012; Wada et al., 2014), RH's 251 sole effect remains unknown. Meteorological factors are interrelated under field conditions; 252 for example, in the Yangtze Valley summer season, which falls between late July and mid253 August, the high temperature is typically coupled with low RH, rainy or cloudy days come 254 with high RH (Guo et al., 2016). Therefore, it is difficult to separate the effect of humidity on 255 crop yield from the complex meteorological factors in a field experiment (Yoshida, 1981; 256 Zhang et al., 2017; Zhao \& Fitzgerald, 2013). We used controlled environmental conditions to 257 simulate three temperatures with two RH regimes to evaluate RH's effects from those of air 258 temperatures on high temperature-induced rice yield and quality loss during the grain-filling 259 stage. Both temperature and RH showed pronounced effects on grain weight, head rice rate, 260 and chalkiness; temperature $\times \mathrm{RH}$ combination showed significantly interactive effects on 261 grain weight and chalkiness (Table 1). Temperature treatments at RH75\% significantly 262 reduced grain weight, and the reduction was greater at RH $85 \%$. The same trend was also 263 observed for grain quality loss. Our study is consistent with Wada et al. (2011), who found 264 that grains were losing quality in dry, hot winds.

\section{The interaction effect of temperature and $\mathrm{RH}$}

During the flowering stage, panicle temperature rather than air temperature was curvilinearly related to spikelet fertility (Weerakoon et al., 2008). Rice could homeostatically adjust panicle temperature via transpiration cooling for optimal growth. The air-panicle temperature difference was altered under different RH conditions (Fukuoka et al., 2012; Yoshimoto et al., 2011). Yan et al. (2008) showed that at temperatures of $31.5-33.5^{\circ} \mathrm{C}$, the temperature difference between the air and panicle was about $2^{\circ} \mathrm{C}$ under humid atmospheric conditions $(\sim 86 \% \mathrm{RH})$ or about $5^{\circ} \mathrm{C}$ under a dry atmospheric condition $(\sim 48 \% \mathrm{RH})$. Rice panicles benefit from their transpiration cooling under heat stress at flowering (Matsui et al., 2014). However, our results showed decreased $\mathrm{RH}$, coupled with a high temperature at the grain filling stage reduced grain weight and lowered grain quality. The benefit from the decreased RH by transpiration cooling may not be the only scenario of $\mathrm{RH}$ and temperature interaction.

Theoretically, there may be a balance between transpiration cooling and a water deficit in rice 
279 panicles exposed to heat. Zhao \& Fitzgerald (2013) reported that a daily maximum temperature 280 ranging from $30^{\circ} \mathrm{C}$ to $33^{\circ} \mathrm{C}$ and a lower $\mathrm{RH}$ led to higher head rice yield and lower chalkiness. 281 Meanwhile, Wada et al. (2011) showed dry winds at day/night temperatures of $34 / 26^{\circ} \mathrm{C}$ caused 282 water deficiencies in panicles and restricted starch accumulation, which led to a decline in the 283 quality of the rice. We found that decreased humidity coupled with temperature treatments 284 caused grain weight reduction and quality loss. This effect was most pronounced at $35^{\circ} \mathrm{C}$, and 285 to a lesser extent at $33^{\circ} \mathrm{C}$, and insignificant at $37^{\circ} \mathrm{C}$. This indicates that transpiration cooling 286 may not be enough to compensate for the adverse effects of water deficit when rice is exposed 287 to high-temperature stress $\left(35^{\circ} \mathrm{C}\right.$ and $\left.33^{\circ} \mathrm{C}\right)$.

288

\section{Physiological mechanism of temperature and RH interaction}

Water fluctuations for growth and transpiration are linearly superimposed (Nonami \& Hossain, 2010), and the impaired ability of stomatal regulation of rice spikelets has a greater evaporative demand under high temperature (Garrity et al., 1986), leaving the spikelets and grains at risk of water deficit (Tanaka \& Matsushima, 1971). Water deficiency in the panicle caused by dry, hot winds was detrimental to rice grain weight and quality formation (Hiroshi et al., 2012; Kang et al., 2003; Wada et al., 2011). Low relative humidity may reduce the assimilation capacity of leaf photosynthesis (Tanaka \& Matsushima, 1971). The normal maturing process of grains is dependent on a sufficient water supply (Cochrane et al., 2000; Ferrise et al., 2015). Thus, a higher temperature with lower humidity may induce high temperature-forced maturity. Panicle water potential is temporarily reduced during periods of dry, hot wind stress (Wada et al., 2011). The osmotic adjustment of endosperm cells with increased transport was activated to maintain kernel growth, but starch biosynthesis was slowed (Wada et al., 2014). The vacuolar structures in the cytosol were preserved during maturity because of osmotic adjustments, resulting in ring-shaped chalkiness (Hatakeyama et al., 2018). High-temperature stress led to substantial solutes to be accumulated in endosperm cells by osmotic adjustment. This was accompanied by the partial inhibition of amyloplast development and the formation of protein bodies, which caused air spaces to remain in endosperm cells during grain dehydration, resulting in a chalky appearance (Wada et al., 2019). Similar mechanisms of starch synthesis restriction were found under high temperature and dry wind conditions, meaning that decreased RH may aggravate the high-temperature effect on grain weight and quality loss.

11 The osmotic regulation ability of plants is closely related to the heat tolerance during the 
312 vegetative growth period (An et al. 2014; Jiang \& Huang 2001; Zhou et al. 2018; Zou et al.

313 2016), and the study of Wada et al. (2014) suggests that this relationship is also applicable at

314 the filling stage of rice. We speculate that the differences in variety performance in this study

315 may be related to osmotic regulation, but further study is needed.

316

\section{Varietal differences under RH in combination with temperature treatments}

318 A daily mean air temperature over $25^{\circ} \mathrm{C}$ during the grain filling stage can cause a loss of quality 319 in the rice grains (Morita et al., 2016; Wu et al., 2016). However, the magnitude of heat stress320 induced damage varied by genotype. Cooper et al. (2008) reported a reduction in grain quality 321 in susceptible cultivars at nighttime temperatures of $20^{\circ} \mathrm{C}$, but this effect was not reflected in 322 heat-tolerant cultivars at the nighttime temperature of $30^{\circ} \mathrm{C}$. We found that grain weight and 323 quality traits did not change linearly with increasing temperatures and only changed 324 dramatically at a certain temperature, with varied responses among different cultivars (Fig. 2, 325 4, and 5). This was similar to the response of spikelet fertility to high temperatures during 326 flowering (Jagadish et al., 2007).

327 The identification of heat-tolerant rice germplasms (e.g., N22) may present opportunities to 328 breed heat-tolerant rice at the flowering stage (González-Schain et al., 2015; Tetsuo \& 329 Shouichi, 1978). The mechanism leading to grain quality losses is more complex than the 330 mechanism of heat-induced yield loss (Jagadish et al., 2015), which brings more challenges 331 for screening and identifying tolerant varieties. Previous studies paid closer attention to 332 temperatures in controlled environments when investigating rice heat tolerance at the grain 333 filling stage (Chen et al., 2017; Shiraya et al., 2015; Tanamachi et al., 2016). We showed that 334 changes in grain weight and quality are affected by interactions between temperature and 335 humidity and found that humidity is important in evaluating varietal heat tolerance. We suggest 336 that the effect of humidity should be considered in multi-variety tolerance screening and 337 identification. The optimum combination of $35^{\circ} \mathrm{C}$ by $\mathrm{RH} 75 \%$ by 15 days should be 338 recommended to screen for heat tolerance of rice. Our results bring attention to the detrimental 339 interactive effects of high temperature and humidity on rice yield and quality and are of interest 340 to breeders and agronomists to adjust breeding targets. R168, the most heat-tolerant cultivar 341 used in this study, showed smaller differences in grain weight and quality between two RH 342 regimes. This variety may be selected as a heat-tolerance variety to improve rice yield and 343 quality under climate change. 


\section{Conclusion}

346 We found that decreased $\mathrm{RH}$ aggravated the detrimental effects of high temperature on grain 347 weight and quality. These effects were the most pronounced at $35^{\circ} \mathrm{C}$, less pronounced at $33^{\circ} \mathrm{C}$, 348 and were not significant at $37^{\circ} \mathrm{C}$. Heat tolerant cultivars were identified and determined to be 349 less affected by the treatments.

350

\section{Acknowledgments}

352 We thank Yizhi Bao, Xiangwen Li, and Qilin Mu for their technical assistance in the field 353 management. 


\section{Reference}

356

357

358

359

360

361

362

363

364

365

366

367

368

369

370

371

372

373

374

375

376

377

378

379

380

381

382

383

384

385

386

387

388

389

390

391

392

Abayawickrama ASMT, Reinke RF, Fitzgerald MA, Harper JDI, and Burrows GE. 2017. Influence of high daytime temperature during the grain filling stage on fissure formation in rice. Journal of Cereal Science 74:256-262. 10.1016/j.jcs.2017.02.013

Ambardekar AA, Siebenmorgen TJ, Counce PA, Lanning SB, and Mauromoustakos A. 2011. Impact of field-scale nighttime air temperatures during kernel development on rice milling quality. Field Crops Research 122:179-185. 10.1016/j.fcr.2011.03.012

An Y, Zhou P, and Liang J. 2014. Effects of exogenous application of abscisic acid on membrane stability, osmotic adjustment, photosynthesis and hormonal status of two lucerne (Medicago sativa L.) genotypes under high temperature stress and drought stress. Crop and Pasture Science 65:274-286. 10.1071/CP13162

Bao J. 2019. 10 - Rice milling quality. In: Bao J, ed. Rice (Fourth Edition): AACC International Press, 339-369.

Byrne MP, and O'Gorman PA. 2016. Understanding decreases in land relative humidity with global warming: Conceptual model and GCM Simulations. Journal of Climate 29:90459061. 10.1175/jcli-d-16-0351.1

Chakraborty B, and Hazari S. 2017. Impact of climate change on yields of major agricultural crops in Tripura. Indian Journal of Agricultural Research 51:399-401.

Chen J, Tang L, Shi P, Yang B, Sun T, Cao W, and Zhu Y. 2017. Effects of short-term high temperature on grain quality and starch granules of rice (Oryza sativa L.) at post-anthesis stage. Protoplasma 254:935-943. 10.1007/s00709-016-1002-y

Chen X, Min D, Yasir TA, and Hu Y-G. 2012. Evaluation of 14 morphological, yield-related and physiological traits as indicators of drought tolerance in Chinese winter bread wheat revealed by analysis of the membership function value of drought tolerance (MFVD). Field Crops Research 137:195-201. 10.1016/j.fcr.2012.09.008

Cochrane MP, Paterson L, and Gould E. 2000. Changes in chalazal cell walls and in the peroxidase enzymes of the crease region during grain development in barley. Journal of experimental botany 51:507-520.

Cooper NTW, Siebenmorgen TJ, and Counce PA. 2008. Effects of nighttime temperature during kernel development on rice physicochemical properties. Cereal Chemistry 85:276-282. 10.1094/cchem-85-3-0276

Cooper NTW, Siebenmorgen TJ, Counce PA, and Meullenet J-F. 2006. Explaining rice milling quality variation using historical weather data analysis. Cereal Chemistry 83:447-450. 10.1094/cc-83-0447

Dai A, Zhao T, and Chen J. 2018. Climate change and drought: A precipitation and evaporation perspective. Current Climate Change Reports 4:301-312. 10.1007/s40641-018-0101-6

F. Thompson J, and G. Mutters R. 2006. Effect of weather and rice moisture at harvest on milling quality of california medium-grain rice. Transactions of the Asabe 49:435-440. 
393

394

395

396

397

398

399

400

401

402

403

404

405

406

407

408

409

410

411

412

413

414

415

416

417

418

419

420

421

422

423

424

425

426

427

428

429

430

10.13031/2013.20392

Ferrise R, Bindi M, and Martre P. 2015. Grain filling duration and glutenin polymerization under variable nitrogen supply and environmental conditions for durum wheat. Field Crops Research 171:23-31. 10.1016/j.fcr.2014.10.016

Fukuoka M, Yoshimoto M, and Hasegawa T. 2012. Varietal range in transpiration conductance of flowering rice panicle and its impact on panicle temperature. Plant Production Science 15:258-264. 10.1626/pps. 15.258

Garrity DP, Vidal ET, and O'Toole JC. 1986. Manipulating panicle transpiration resistance to increase rice spikelet fertility during flowering stage water stress. Crop Science 26:789795. 10.2135/cropsci1986.0011183X002600040034x

Gong L, Xu C-y, Chen D, Halldin S, and Chen YD. 2006. Sensitivity of the Penman-Monteith reference evapotranspiration to key climatic variables in the Changjiang (Yangtze River) basin. Journal of Hydrology 329:620-629. 10.1016/j.jhydrol.2006.03.027

González-Schain N, Dreni L, Lawas LMF, Galbiati M, Colombo L, Heuer S, Jagadish KSV, and Kater MM. 2015. Genome-wide transcriptome analysis during anthesis reveals new insights into the molecular basis of heat stress responses in tolerant and sensitive rice varieties. Plant and Cell Physiology 57:57-68. 10.1093/pcp/pcv174

Guan Y, Zhang X, Zheng F, and Wang B. 2015. Trends and variability of daily temperature extremes during 1960-2012 in the Yangtze River Basin, China. Global and Planetary Change 124:79-94. 10.1016/j.gloplacha.2014.11.008

Guo W, Wang X, Sun J, Ding A, and Zou J. 2016. Comparison of land-atmosphere interaction at different surface types in the mid- to lower reaches of the Yangtze River valley. Atmos Chem Phys 16:9875-9890. 10.5194/acp-16-9875-2016

Hakata M, Kuroda M, Miyashita T, Yamaguchi T, Kojima M, Sakakibara H, Mitsui T, and Yamakawa H. 2012. Suppression of $\alpha$-amylase genes improves quality of rice grain ripened under high temperature. Plant biotechnology journal 10:1110-1117. 10.1111/j.14677652.2012.00741.x

Hatakeyama Y, Masumoto-Kubo C, Nonami H, Morita S, Hiraoka K, Onda Y, Nakashima T, Nakano H, and Wada H. 2018. Evidence for preservation of vacuolar compartments during foehn-induced chalky ring formation of Oryza sativa L. Planta 248:1263-1275. 10.1007/s00425-018-2975-x

Hiroshi W, Hiroshi N, Yabuoshi Y, Fukuyo T, Atsushi M, Akio T, Kenichi W, Kazuo W, Tomohiko S, Yasuyuki W, and Satoshi M. 2012. Mechanism for the formation of ringshaped chalkiness in growing rice kernels under typhoon/foehn-induced dry wind condition and its practical applications. Abstracts of Meeting of the CSSJ 233:190-190. 10.14829/jcsproc.233.0.190.0

Jagadish SVK, Craufurd PQ, and Wheeler TR. 2007. High temperature stress and spikelet fertility in rice (Oryza sativa L.). Journal of experimental botany 58:1627-1635. 
431

432

433

434

435

436

437

438

439

440

441

442

443

444

445

446

447

448

449

450

451

452

453

454

455

456

457

458

459

460

461

462

463

464

465

466

467

468

10.1093/jxb/erm003

Jagadish SVK, Murty MVR, and Quick WP. 2015. Rice responses to rising temperatures challenges, perspectives and future directions. Plant Cell Environ 38:1686-1698. $10.1111 /$ pce. 12430

Jiang Y, and Huang B. 2001. Osmotic adjustment and root growth associated with drought preconditioning-enhanced heat tolerance in kentucky bluegrass. Crop Science 41:11681173. 10.2135/cropsci2001.4141168x

Kang D-J, Yeo U-s, Oh B-g, Kang J-h, Yang S-j, Ishil R, and Lee I-j. 2003. Physiological studies on the foehn tolerance of rice. Japanese Journal of Crop Science 72:328-332. $10.1626 /$ jcs. 72.328

Liu C, Yang Z, and Hu Y-G. 2015. Drought resistance of wheat alien chromosome addition lines evaluated by membership function value based on multiple traits and drought resistance index of grain yield. Field Crops Research 179:103-112. 10.1016/j.fcr.2015.04.016

Liu K, Deng J, Lu J, Wang X, Lu B, Tian X, and Zhang Y. 2019. High nitrogen levels alleviate yield loss of super hybrid rice caused by high temperatures during the flowering stage. Front Plant Sci 10. 10.3389/fpls.2019.00357

Lyman NB, Jagadish KSV, Nalley LL, Dixon BL, and Siebenmorgen T. 2013. Neglecting rice milling yield and quality underestimates economic losses from high-temperature stress. Plos One 8. 10.1371/journal.pone.0072157

Matsui T, Kobayasi K, Nakagawa H, Yoshimoto M, Hasegawa T, Reinke R, and Angus J. 2014. Lower-than-expected floret sterility of rice under extremely hot conditions in a floodirrigated field in New South Wales, Australia. Plant Production Science 17:245-252. 10.1626/pps.17.245

Morita S, Wada H, and Matsue Y. 2016. Countermeasures for heat damage in rice grain quality under climate change. Plant Production Science 19:1-11. 10.1080/1343943X.2015.1128114

Nonami H, and Hossain MM. 2010. Superposition of the transpiration-induced water potential and the growth-induced water potential associated with expanding tomato leaves. Environmental Control in Biology 48:117-125. 10.2525/ecb.48.117

Orimoloye IR, Mazinyo SP, Nel W, and Iortyom ET. 2018. Assessing changes in climate variability observation and simulation of temperature and relative humidity: a case of east london, South Africa. Research Journal of Environmental Sciences 12:1-13.

Oya K, and Yoshida T. 2008. Effects of the Period of the Ventilation on Occurrence of "Chalky Grains" in Rice. Japanese Journal of Crop Science 77:434-442. 10.1626/jcs.77.434

Peng S, Huang J, Sheehy JE, Laza RC, Visperas RM, Zhong X, Centeno GS, Khush GS, and Cassman KG. 2004. Rice yields decline with higher night temperature from global warming. Proceedings of the National Academy of Sciences 101:9971-9975. 10.1073/pnas.0403720101

PeerJ reviewing PDF | (2020:04:47970:6:0:NEW 28 Feb 2021) 
469 Po-Chedley S, Zelinka M, Jeevanjee N, and Santer BD. 2018. Climatological constraint on tropical

470

471

472

473

474

475

476

477

478

479

480

481

482

483

484

485

486

487

488

489

490

491

492

493

494

495

496

497

498

499

500

501

502

503

504

505

506 relative humidity changes. AGU Fall Meeting Abstracts. p A21H-2781.

Seck PA, Diagne A, Mohanty S, and Wopereis MCS. 2012. Crops that feed the world 7: Rice. Food Security 4:7-24. 10.1007/s12571-012-0168-1

Shiraya T, Mori T, Maruyama T, Sasaki M, Takamatsu T, Oikawa K, Itoh K, Kaneko K, Ichikawa H, and Mitsui T. 2015. Golgi/plastid-type manganese superoxide dismutase involved in heat-stress tolerance during grain filling of rice. Plant biotechnology journal 13:12511263. 10.1111/pbi.12314

Stocker T, Qin D, Plattner G, Tignor M, Allen S, Boschung J, Nauels A, and Xia Y. 2013. IPCC, 2013: summary for policymakers in climate change 2013: the physical science basis, contribution of working group I to the fifth assessment report of the intergovernmental panel on climate change. Cambridge University Press, Cambridge, United Kingdom and New York, NY,USA.

Tan S, and Shen S. 2016. Distribution of rice heat stress in the lower yangtze region in recent 32 years. Jiangsu agricultural sciences 44:97-101(In Chinese).

Tanaka T, and Matsushima S. 1971. Analysis of yield-determining process and its application to yield-prediction and culture improvement of lowland rice : CIII. On factors affecting the light-curves of carbon assimilation in rice plant communities. Japanese Journal of Crop Science 40:366-375. 10.1626/jcs.40.366

Tanamachi K, Miyazaki M, Matsuo K, Suriyasak C, Tamada A, Matsuyama K, Iwaya-Inoue M, and Ishibashi Y. 2016. Differential responses to high temperature during maturation in heat-stress-tolerant cultivars ofJaponicarice. Plant Production Science 19:300-308. 10.1080/1343943x.2016.1140007

Tetsuo S, and Shouichi Y. 1978. High temperature-induced sterility in indica rices at flowering. Japanese Journal of Crop Science 47:6-17.

Tian X, Matsui T, Li S, Yoshimoto M, Kobayasi K, and Hasegawa T. 2010. Heat-Induced floret sterility of hybrid rice (Oryza sativa L.) cultivars under humid and low wind conditionsin the field of Jianghan Basin, China. Plant Production Science 13:243-251.

Venables WN, Ripley BD, and Venables WN. 2002. Modern applied statistics with S. New York: Springer.

Wada H, Hatakeyama Y, Onda Y, Nonami H, Nakashima T, Erra-Balsells R, Morita S, Hiraoka K, Tanaka F, and Nakano H. 2019. Multiple strategies for heat adaptation to prevent chalkiness in the rice endosperm. Journal of experimental botany 70:1299-1311. $10.1093 / j x b / e r y 427$

Wada H, Masumoto-Kubo C, Gholipour Y, Nonami H, Tanaka F, Erra-Balsells R, Tsutsumi K, Hiraoka K, and Morita S. 2014. Rice chalky ring formation caused by temporal reduction in starch biosynthesis during osmotic adjustment under foehn-induced dry wind. Plos One 9:e110374-e110374. 10.1371/journal.pone.0110374 
507 Wada H, Nonami H, Yabuoshi Y, Maruyama A, Tanaka A, Wakamatsu K, Sumi T, Wakiyama Y, 508 Ohuchida M, and Morita S. 2011. Increased ring-shaped chalkiness and osmotic

509

510

511

512

513

514

515

516

517

518

519

520

521

522

523

524

525

526

527

528

529

530

531

532

533

534

535

536

537

538

539

540

541

542

543

544 adjustment when growing rice grains under foehn-induced dry wind condition. Crop Science 51:1703-1715. 10.2135/cropsci2010.08.0503

Weerakoon WMW, Maruyama A, and Ohba K. 2008. Impact of humidity on temperature-induced grain sterility in rice (Oryza sativa L.). Journal of Agronomy and Crop Science 194:135140. 10.1111/j.1439-037X.2008.00293.x

Wu Y-C, Chang S-J, and Lur H-S. 2016. Effects of field high temperature on grain yield and quality of a subtropical type japonica rice-Pon-Lai rice. Plant Production Science 19:145153. 10.1080/1343943X.2015.1128091

Yamakawa H, and Hakata M. 2010. Atlas of rice grain filling-related metabolism under high temperature: Joint analysis of metabolome and transcriptome demonstrated inhibition of starch accumulation and induction of amino acid accumulation. Plant and Cell Physiology 51:795-809. 10.1093/pcp/pcq034

Yamakawa H, Hirose T, Kuroda M, and Yamaguchi T. 2007. Comprehensive expression profiling of rice grain filling-related genes under high temperature using DNA microarray. Plant Physiol 144:258.

Yan C, Ding Y-f, Liu Z-h, Wang Q-s, Li G-h, He Y, and Wang S-h. 2008. Temperature difference between the air and organs of rice plant and its relation to spikelet fertility. Agricultural Sciences in China 7:678-685. 10.1016/S1671-2927(08)60102-9

Yan H, Zhang B, Zhang Y, Chen X, Xiong H, Matsui T, and Tian X. 2017. High temperature induced glume closure resulted in lower fertility in hybrid rice seed production. Front Plant Sci 7:1960. 10.3389/fpls.2016.01960

Yoshida S. 1981. Fundamentals of rice crop science: Int. Rice Res. Inst.

Yoshimoto M, Fukuoka M, Hasegawa T, Matsui T, Tian X, Vijayalakshmi C, Singh MP, MYINT TT, Weerakoon W, and Lafarge T. 2012. MINCERnet: a global research alliance to support the fight against heat stress in rice. Journal of Agricultural Meteorology 68:149-157.

Yoshimoto M, Fukuoka M, Hasegawa T, Utsumi M, Ishigooka Y, and Kuwagata T. 2011. Integrated micrometeorology model for panicle and temperature (IM2PACT) for rice heat stress studies under climate change. Journal of Agricultural Meteorology 67:233-247.

Zadeh LA. 1965. Fuzzy sets. Information and Control 8:338-353. 10.1016/S0019-9958(65)90241$\mathrm{X}$

Zakaria S, Matsuda T, Tajima S, and Nitta Y. 2002. Effect of high temperature at ripening stage on the reserve accumulation in seed in some rice cultivars. Plant Production Science 5:160168. 10.1626/pps.5.160

Zhang CX, Feng BH, Chen TT, Fu WM, Li HB, Li GY, Jin QY, Tao LX, and Fu GF. 2018a. Heat stress-reduced kernel weight in rice at anthesis is associated with impaired source-sink relationship and sugars allocation. Environmental and Experimental Botany 155:718-733. 
$545 \quad$ 10.1016/j.envexpbot.2018.08.021

546 Zhang L, Yang B, Li S, Hou Y, and Huang D. 2018b. Potential rice exposure to heat stress along 547 the Yangtze River in China under RCP8.5 scenario. Agricultural and Forest Meteorology $548 \quad$ 248:185-196. 10.1016/j.agrformet.2017.09.020

549 Zhang P, Zhang J, and Chen M. 2017. Economic impacts of climate change on agriculture: The 550 importance of additional climatic variables other than temperature and precipitation. 551 Journal of Environmental Economics and Management 83:8-31. $552 \quad$ 10.1016/j.jeem.2016.12.001

553 Zhao X, and Fitzgerald M. 2013. Climate change: implications for the yield of edible rice. Plos $554 \quad$ One 8:e66218. 10.1371/journal.pone.0066218

555 Zhou H, Yun P, and He Y. 2019. 11 - Rice appearance quality. In: Bao J, ed. Rice (Fourth Edition): 556 AACC International Press, 371-383.Zhou Z-H, Wang Y, Ye X-Y, and Li Z-G. 2018.

564

565

566

567

568 signaling molecule hydrogen sulfide improves seed germination and seedling growth of maize (Zea mays 1.) under high temperature by inducing antioxidant system and osmolyte biosynthesis. Front Plant Sci 9. 10.3389/fpls.2018.01288

Zou M, Yuan L, Zhu S, Liu S, Ge J, and Wang C. 2016. Response of osmotic adjustment and ascorbate-glutathione cycle to heat stress in a heat-sensitive and a heat-tolerant genotype of wucai (Brassica campestris L.). Scientia Horticulturae 211:87-94. 10.1016/j.scienta.2016.08.011 
569 Figures

570

571 Figure 1: Diagram of all treatments (A), temperature and RH diurnal variation, maximum 572 temperature, average temperature, minimum temperature, and average $\mathrm{RH}$ in each 573 treatment (B-G). The measured value was the average of $15 \mathrm{~d}$ and the shading around the 574 measured value indicates the standard error of the measured values of $15 \mathrm{~d}$.

575

576

Figure 2: Grain weight responses to different treatments. (A) LY27, (B) LY6, (C) ZLY47, (D)

577 R168, (E) IR64, and (F) 16343. Vertical bars denote standard deviations ( $\mathrm{n}=3)$, a different letter

578 in the lowercase indicates significant differences among means of different treatments as 579 determined by the LSD test $(p<0.05)$.

580

581

Figure 3: Boxplot shows the difference between relative humidity treatments (RH75\% vs.

582

583

584

585

586

587

588

589

590

591

592

Figure 5: Chalkiness responses to different treatments. (A) LY27, (B) LY6, (C) ZLY47, (D) 593 R168, (E) IR64, and (F) 16343. Vertical bars denote standard deviations $(n=3)$, a different letter in the lowercase indicates significant differences among means of different treatments as

595

596 $\mathbf{R H 8 5 \%}$ ) in different temperature treatments and durations. (A) grain weight, (B) head rice rate, and (C) Chalkiness. Data for each boxplot are the value at RH75\% minus the value at RH85\% under each temperature $\times$ duration treatment of 6 cultivars.

Figure 4: Head rice rate responses to different treatments. (A) LY27, (B) LY6, (C) ZLY47, (D) R168, (E) IR64, and (F) 16343. Vertical bars denote standard deviations $(\mathrm{n}=3)$, a different letter in the lowercase indicates significant differences among means of different treatments as determined by the LSD test $(p<0.05)$. 


\section{Tables}

598

599 Table 1:

600 Summary of ANOVA for grain weight, head rice rate, and chalkiness in each cultivar.

601 Factors: Temperature (T), Relative humidity (RH), Duration days (D). Data are F-values with

602 indication of significance levels ( $* \mathrm{P}<0.05 ; * * \mathrm{P}<0.01 ; * * * \mathrm{P}<0.001)$.

603

604 Table 2:

605 Parameter estimation, $\mathbf{r}$ square, and F-value of multiple regression. The asterisks near the 606 coefficient value indicates significance at $* * *(\mathrm{P}<.001), * *(\mathrm{P}<.01), *(\mathrm{P}<.05)$. "-" represent the

607 variable was dropped in the final model. $\mathrm{X}_{1}$, max daily temperature $\left({ }^{\circ} \mathrm{C}\right) ; \mathrm{X}_{2}$, relative humidity $608(\%) ; \mathrm{X}_{3}$, duration days $(\mathrm{d}) ; \mathrm{X}_{4}$, value of each cultivar under controlled conditions.

609

610 Table 3:

611 Membership function values (MFVs) of grain weight, head rice rate, and chalkiness for each 612 cultivar in each treatment.

613

614 


\section{Supplementary Tables}

616

617 Table S1 Heading date, daily mean temperature during 15 days after heading (T15), daily 618 mean relative humidity during 15 days after heading (RH15), grain weight, head rice rate, 619 and chalkiness of each cultivar in field trial in 2016.

620

621 Table S2 Heading date, daily mean temperature during 15 days after heading (T15), and

622 daily mean relative humidity during 15 days after heading (RH15) of each cultivar. 


\section{Figure 1}

Diagram of all treatments $(\mathrm{A})$, temperature and $\mathrm{RH}$ diurnal variation, maximum temperature, average temperature, minimum temperature, and average $\mathrm{RH}$ in each treatment (B-G).

The measured value was the average of $15 d$, and the shading around the measured value indicates the standard error of the measured values of $15 \mathrm{~d}$. 


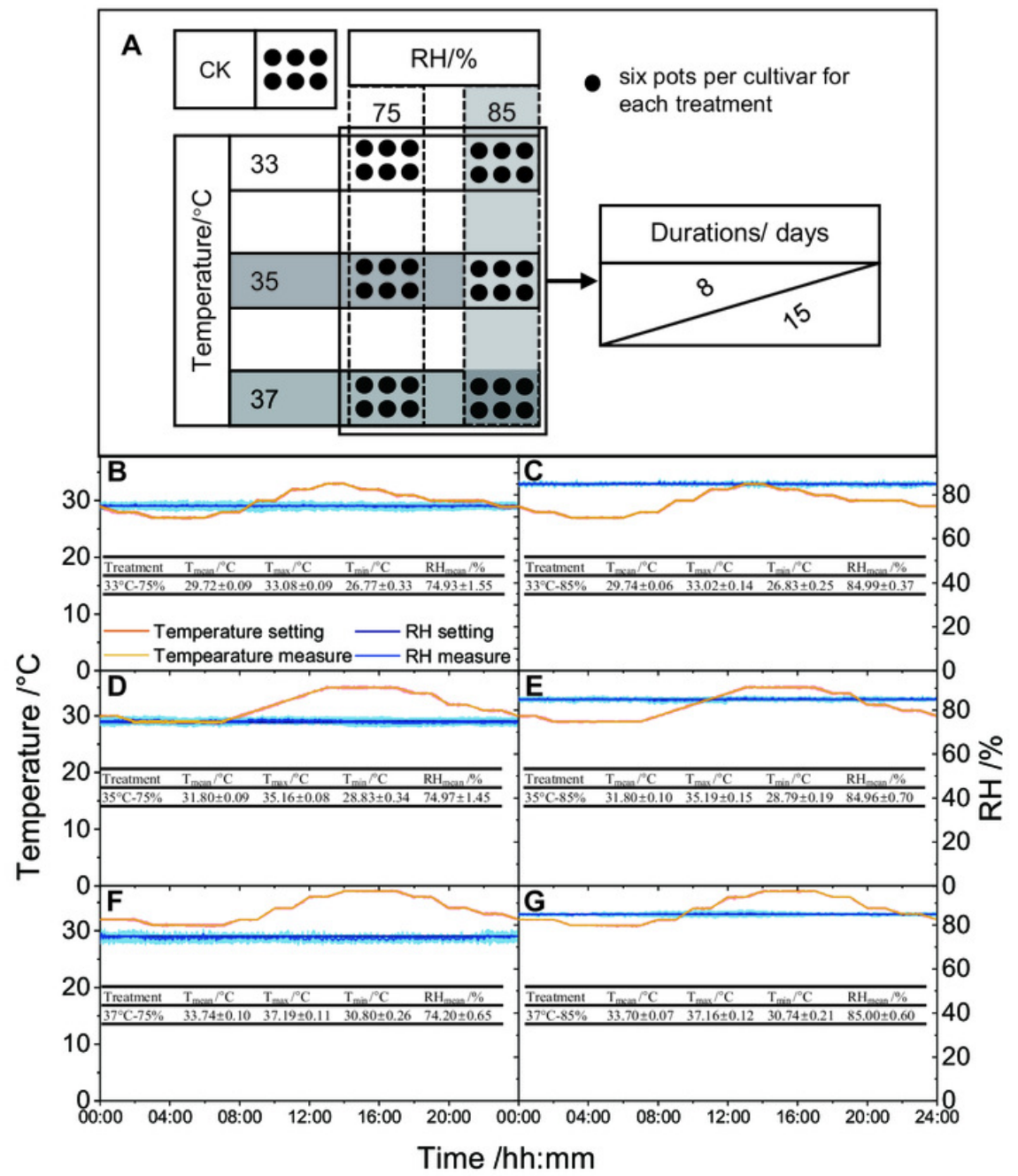


Figure 2

Grain weight responses to different treatments.

(A) LY27, (B) LY6, (C) ZLY47, (D) R168, (E) IR64, and (F) 16343. Vertical bars denote standard deviations ( $n=3)$, a different letter in the lowercase indicates significant differences among means of different treatments as determined by the LSD test $(p<0.05)$. 

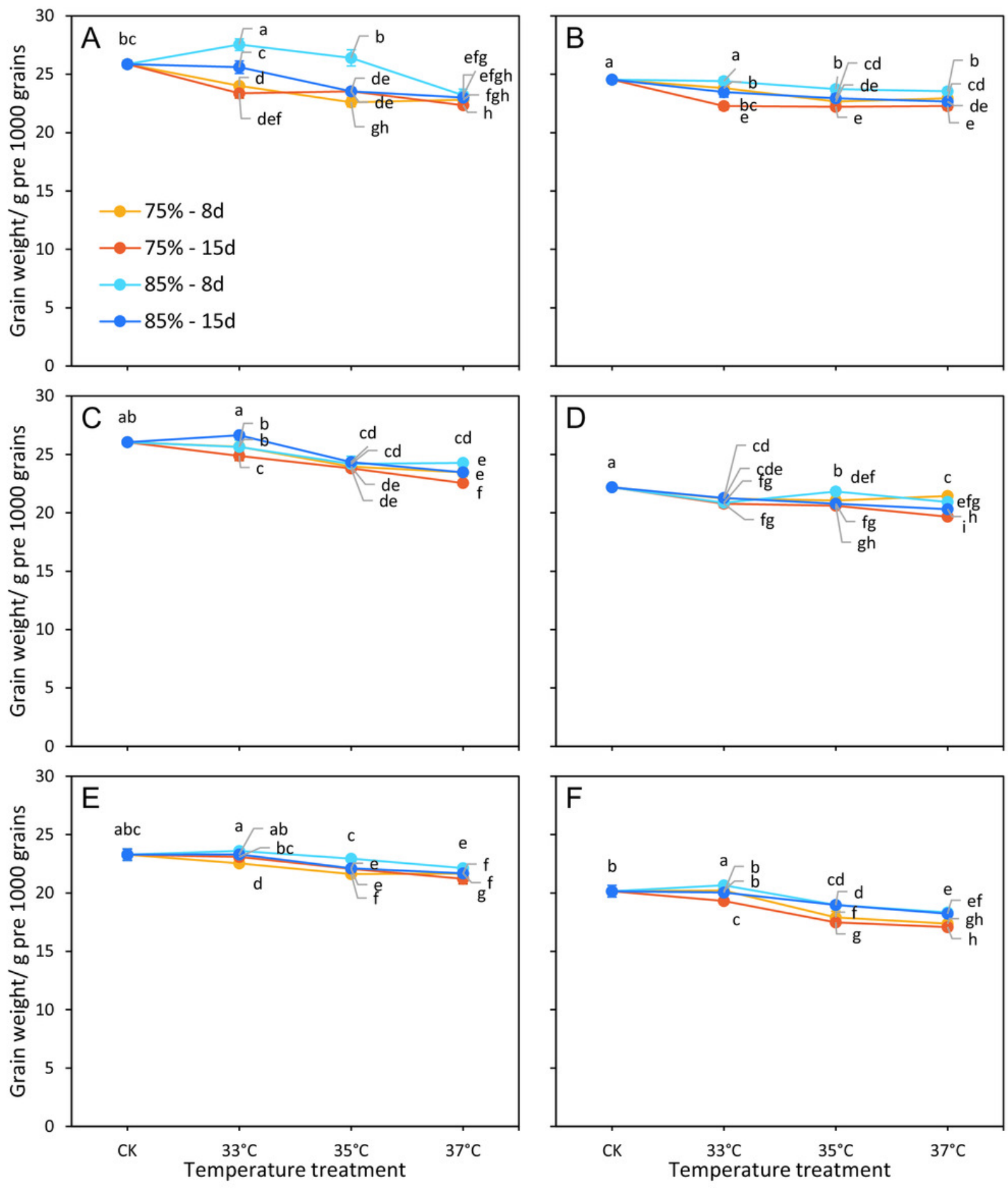
Figure 3

Boxplot shows the difference between relative humidity treatments (RH75\% vs. RH85\%) in different temperature treatments and durations.

(A) grain weight, (B) head rice rate and, (C) Chalkiness. Data for each boxplot are the value at $\mathrm{RH} 75 \%$ minus the value at $\mathrm{RH} 85 \%$ under each temperature $\times$ duration treatment of 6 cultivars .
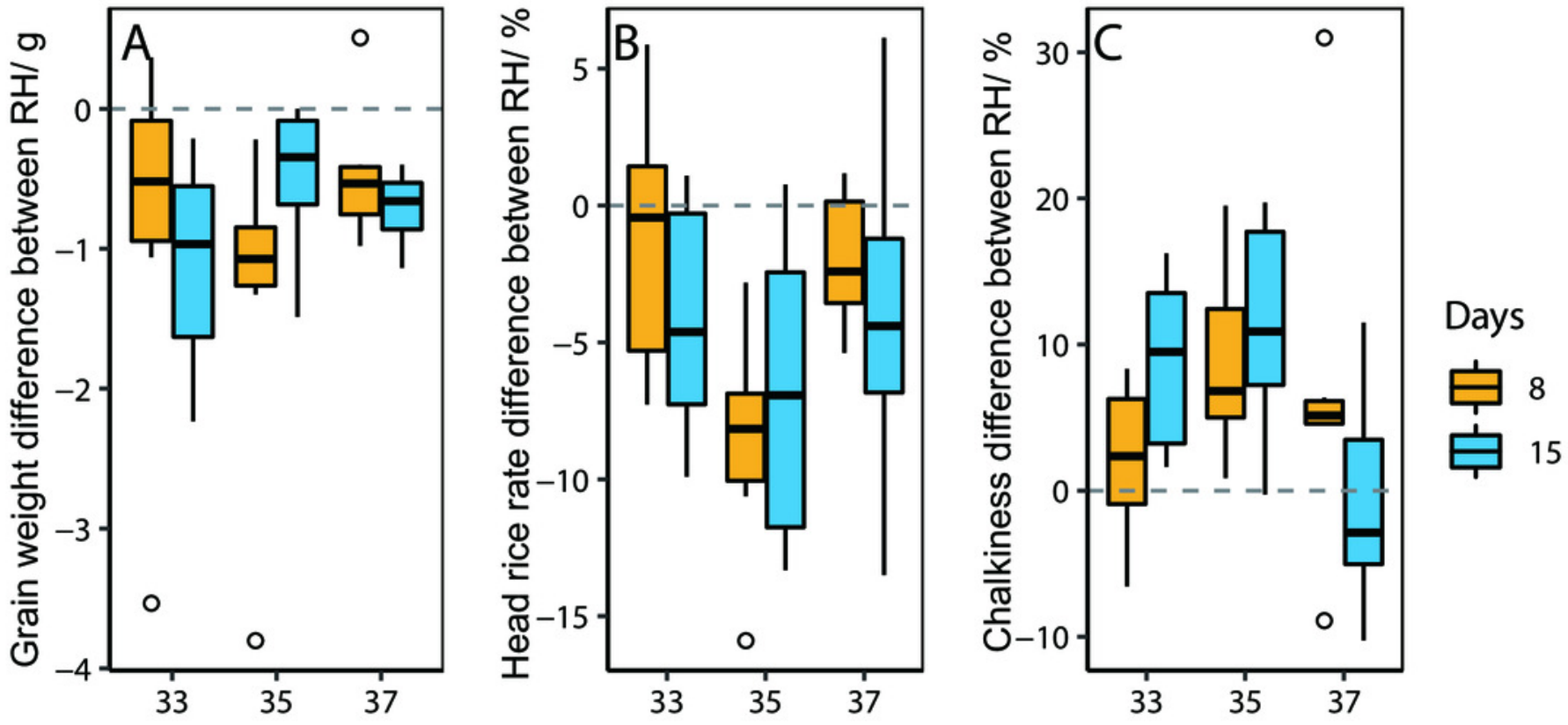

Temperature treatment $/{ }^{\circ} \mathrm{C}$ 
Figure 4

Head rice rate responses to different treatments.

(A) LY27, (B) LY6, (C) ZLY47, (D) R168, (E) IR64, and (F) 16343. Vertical bars denote standard deviations ( $n=3)$, a different letter in the lowercase indicates significant differences among means of different treatments as determined by the LSD test $(p<0.05)$. 

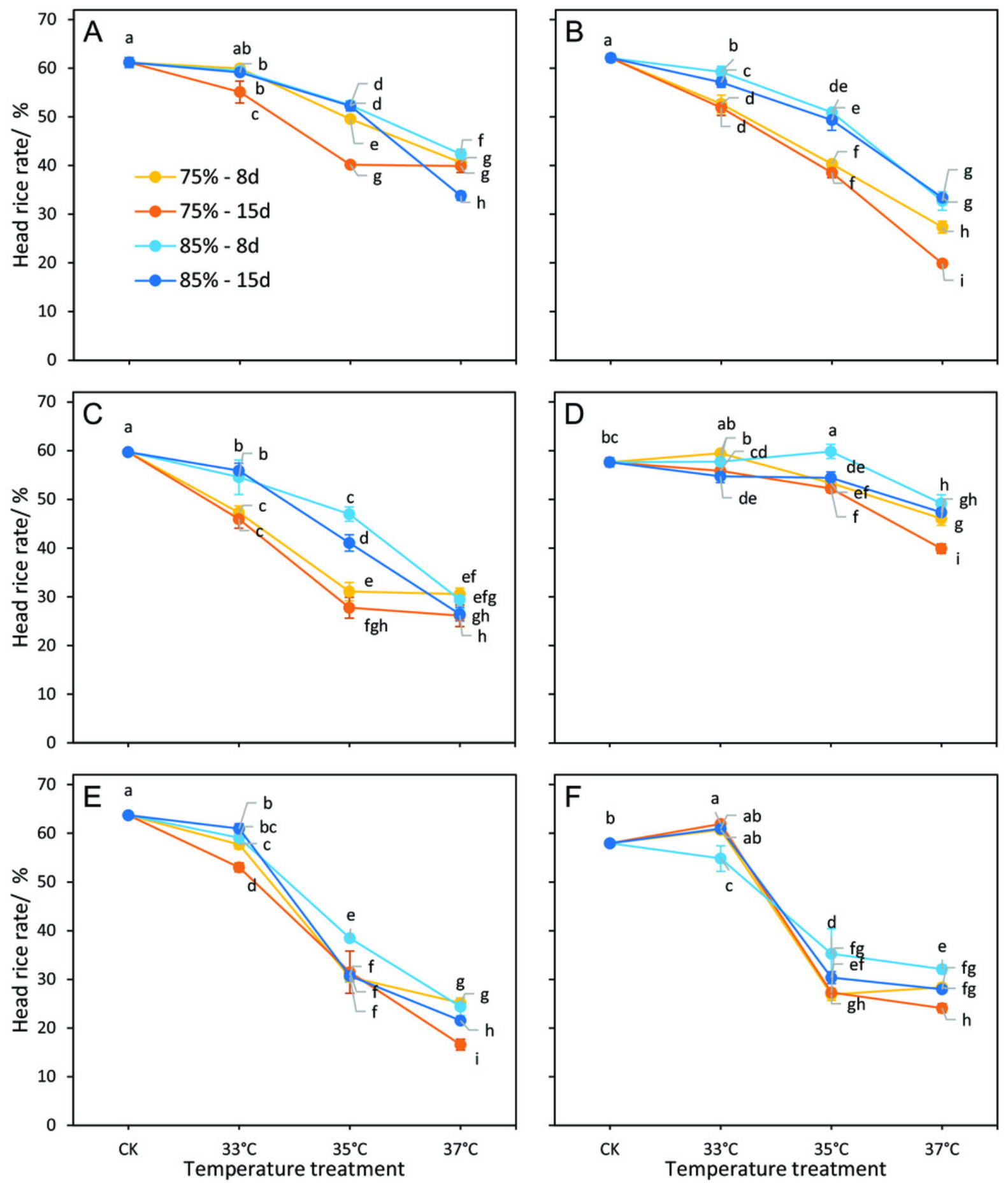


\section{Figure 5}

Chalkiness responses to different treatments.

(A) LY27, (B) LY6, (C) ZLY47, (D) R168, (E) IR64, and (F) 16343. Vertical bars denote standard deviations ( $n=3)$, a different letter in the lowercase indicates significant differences among means of different treatments as determined by the LSD test $(p<0.05)$. 

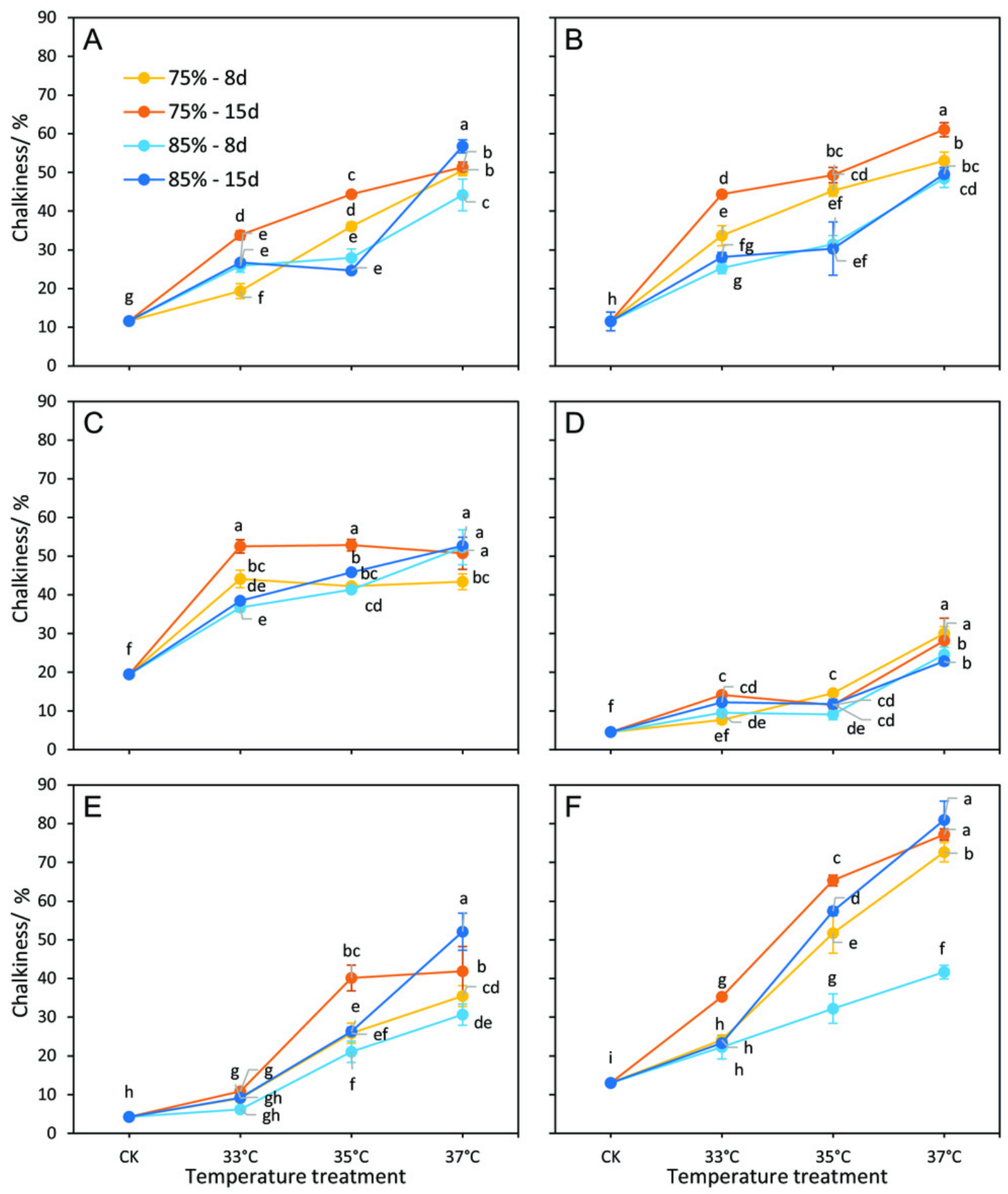


\section{Table $\mathbf{1}$ (on next page)}

Summary of ANOVA for grain weight, head rice rate, and chalkiness in each cultivar

Factors: Temperature $(\mathrm{T})$, Relative humidity $(\mathrm{RH})$, Duration days $(\mathrm{D})$. Data are F-values with indication of significance levels $(* P<0.05 ; * * P<0.01 ; * * * P<0.001)$. 
1

\begin{tabular}{|c|c|c|c|c|}
\hline Cultivars & Factor & Grain weight & Head rice rate & Chalkiness \\
\hline \multirow[t]{7}{*}{ LY27 } & $\mathrm{T}$ & $506.53 * * *$ & $81.25 * * *$ & $1296.53 * * *$ \\
\hline & RH & $55.35 * * *$ & $145.72 * * *$ & $60.14 * * *$ \\
\hline & $\mathrm{D}$ & $77.77 * * *$ & $34.40 * * *$ & $168.07 * * *$ \\
\hline & $\mathrm{T} \times \mathrm{RH}$ & $42.66^{* * *}$ & $21.54 * * *$ & $88.60 * * *$ \\
\hline & $\mathrm{T} \times \mathrm{D}$ & 3.02 & $3.62 *$ & $7.31 * *$ \\
\hline & $\mathrm{RH} \times \mathrm{D}$ & $7.26^{*}$ & $30.11 * * *$ & $8.44 * *$ \\
\hline & $\mathrm{T} \times \mathrm{RH} \times \mathrm{D}$ & $41.25 * * *$ & $16.27 * * *$ & $73.24 * * *$ \\
\hline \multirow[t]{7}{*}{ LY6 } & $\mathrm{T}$ & $178.54 * * *$ & $13.45 * * *$ & $1340.38 * * *$ \\
\hline & RH & $188.26 * * *$ & $46.68 * * *$ & $413.12 * * *$ \\
\hline & $\mathrm{D}$ & $22.82 * * *$ & $61.19 * * *$ & $26.03 * * *$ \\
\hline & $\mathrm{T} \times \mathrm{RH}$ & $7.45^{* *}$ & 1.41 & $11.26 * * *$ \\
\hline & $\mathrm{T} \times \mathrm{D}$ & 2.95 & 2.63 & 2.08 \\
\hline & $\mathrm{RH} \times \mathrm{D}$ & $14.01 * *$ & 0.01 & $7.18^{*}$ \\
\hline & $\mathrm{T} \times \mathrm{RH} \times \mathrm{D}$ & 0.21 & 1.69 & $11.90 * * *$ \\
\hline \multirow[t]{7}{*}{ ZLY47 } & $\mathrm{T}$ & $23.07 * * *$ & $86.81 * * *$ & $429.42 * * *$ \\
\hline & RH & $13.24 * *$ & $23.61 * * *$ & $147.61 * * *$ \\
\hline & $\mathrm{D}$ & $49.20 * * *$ & 2.95 & $21.10 * * *$ \\
\hline & $\mathrm{T} \times \mathrm{RH}$ & $38.45 * * *$ & 1.28 & $50.57 * * *$ \\
\hline & $\mathrm{T} \times \mathrm{D}$ & 2.03 & $4.58^{*}$ & $4.60 *$ \\
\hline & $\mathrm{RH} \times \mathrm{D}$ & $18.33 * * *$ & $6.63^{*}$ & 0.13 \\
\hline & $\mathrm{T} \times \mathrm{RH} \times \mathrm{D}$ & 0.03 & 3.38 & 1.59 \\
\hline \multirow[t]{7}{*}{ R168 } & $\mathrm{T}$ & $190.41 * * *$ & $23.13 * * *$ & $343.66^{* * *}$ \\
\hline & RH & $13.46^{* *}$ & $9.86^{* *}$ & $52.80 * * *$ \\
\hline & $\mathrm{D}$ & 1.41 & $105.14 * * *$ & $87.47 * * *$ \\
\hline & $\mathrm{T} \times \mathrm{RH}$ & $4.42 *$ & $4.30^{*}$ & $30.89 * * *$ \\
\hline & $\mathrm{T} \times \mathrm{D}$ & $6.76 * *$ & $28.38 * * *$ & 0.4 \\
\hline & $\mathrm{RH} \times \mathrm{D}$ & 0.24 & $13.40 * *$ & 0.12 \\
\hline & $\mathrm{T} \times \mathrm{RH} \times \mathrm{D}$ & $3.59 *$ & $18.31 * * *$ & $11.08 * * *$ \\
\hline \multirow[t]{7}{*}{ IR64 } & $\mathrm{T}$ & $339.68 * * *$ & $244.91 * * *$ & $1541.63 * * *$ \\
\hline & RH & $6.84^{*}$ & $121.39 * * *$ & $7.47^{*}$ \\
\hline & $\mathrm{D}$ & $62.03 * * *$ & $9.80 * *$ & $46.94 * * *$ \\
\hline & $\mathrm{T} \times \mathrm{RH}$ & $11.16^{* * *}$ & 1.41 & $22.22 * * *$ \\
\hline & $\mathrm{T} \times \mathrm{D}$ & $11.92 * * *$ & $9.42 * * *$ & $3.91 *$ \\
\hline & $\mathrm{RH} \times \mathrm{D}$ & 0.73 & $40.74 * * *$ & $33.28 * * *$ \\
\hline & $\mathrm{T} \times \mathrm{RH} \times \mathrm{D}$ & $11.53 * * *$ & $12.01 * * *$ & 0.15 \\
\hline \multirow[t]{4}{*}{16343} & $\mathrm{~T}$ & $825.01 * * *$ & $437.00 * * *$ & $948.33 * * *$ \\
\hline & RH & $119.69 * * *$ & $216.44 * * *$ & $11.84 * *$ \\
\hline & $\mathrm{D}$ & $285.66 * * *$ & $35.24 * * *$ & 3.2 \\
\hline & $\mathrm{T} \times \mathrm{RH}$ & $4.36^{*}$ & $9.57 * * *$ & $16.78 * * *$ \\
\hline
\end{tabular}




$\begin{array}{llll}\mathrm{T} \times \mathrm{D} & 26.94 * * * & 7.34 * * & 13.79 * * * \\ \mathrm{RH} \times \mathrm{D} & 44.35^{* * *} & 4.63 * & 0.04 \\ \mathrm{~T} \times \mathrm{RH} \times \mathrm{D} & 49.06 * * * & 0.3 & 5.00^{*}\end{array}$

2 


\section{Table 2 (on next page)}

Parameter estimation, $r$ square, and F-value of multiple regression.

The asterisks near the coefficient value indicates significance at $* * *(\mathrm{P}<.001), * *(\mathrm{P}<.01)$, $*(\mathrm{P}<.05)$. "-" represent the variable was dropped in the final model. $\mathrm{X}_{1}$, max daily temperature $\left({ }^{\circ} \mathrm{C}\right) ; \mathrm{X}_{2}$, relative humidity $(\%) ; \mathrm{X}_{3}$, duration days $(\mathrm{d}) ; \mathrm{X}_{4}$, value of each cultivar under controlled conditions. 


\begin{tabular}{llll}
\hline \multicolumn{1}{c}{ Variables } & \multicolumn{3}{c}{ Coefficient } \\
\cline { 2 - 4 } & Grain weight & Head rice rate & \multicolumn{1}{c}{ Chalkiness } \\
\hline $\mathrm{X}_{1}$ & $-0.3918^{* * *}$ & $-6.0261^{* * *}$ & $40.0446^{* *}$ \\
$\mathrm{X}_{2}$ & $0.0837^{* * *}$ & $0.4666^{* * *}$ & $14.9749^{*}$ \\
$\mathrm{X}_{3}$ & $-0.0764^{* * *}$ & $-0.4154^{* * *}$ & $123.0023^{* *}$ \\
$\mathrm{X}_{4}$ & $0.9153^{* * *}$ & $-0.8432^{* * *}$ & $1.8826^{* * *}$ \\
$\mathrm{X}_{1} \mathrm{X}_{2}$ & - & - & $-0.4405^{* *}$ \\
$\mathrm{X}_{1} \mathrm{X}_{3}$ & - & - & $-3.4569^{* *}$ \\
$\mathrm{X}_{2} \mathrm{X}_{3}$ & - & - & $-1.5463^{* *}$ \\
$\mathrm{X}_{1} \mathrm{X}_{2} \mathrm{X}_{3}$ & - & - & $0.0438^{* *}$ \\
$\mathrm{e}$ (intercept) & $8.4565^{* * *}$ & $272.5611^{* * *}$ & $-1361.0483^{* *}$ \\
$\mathrm{R}^{2}$ & 0.8869 & 0.6513 & 0.6989 \\
Adjusted $\mathrm{R}^{2}$ & 0.8862 & 0.6490 & 0.6944 \\
F-value & $1260.52^{* * *}$ & $283.47^{* * *}$ & $155.82^{* * *}$ \\
\hline
\end{tabular}

1 


\section{Table 3 (on next page)}

Membership function values (MFVs) of grain weight, head rice rate, and chalkiness for each cultivar in each treatment. 


\begin{tabular}{|c|c|c|c|c|c|c|c|}
\hline Cultivars & $\begin{array}{c}\text { Temperatur } \\
\text { e } /{ }^{\circ} \mathrm{C}\end{array}$ & $\mathrm{RH} / \%$ & $\begin{array}{c}\text { Duration } \\
\text { days }\end{array}$ & $\begin{array}{c}\text { MFV of } \\
\text { grain } \\
\text { weight }\end{array}$ & $\begin{array}{c}\text { MFV of } \\
\text { head rice } \\
\text { rate }\end{array}$ & $\begin{array}{c}\text { MFV of } \\
\text { chalkiness }\end{array}$ & Mean \\
\hline \multirow[t]{12}{*}{ LY27 } & 33 & 75 & 8 & 0.37 & 0.89 & 0.82 & 0.70 \\
\hline & & & 15 & 0.26 & 0.79 & 0.63 & 0.56 \\
\hline & & 85 & 8 & 1.00 & 0.88 & 0.74 & 0.87 \\
\hline & & & 15 & 0.66 & 0.87 & 0.73 & 0.75 \\
\hline & 35 & 75 & 8 & 0.12 & 0.68 & 0.60 & 0.47 \\
\hline & & & 15 & 0.29 & 0.49 & 0.49 & 0.42 \\
\hline & & 85 & 8 & 0.80 & 0.74 & 0.71 & 0.75 \\
\hline & & & 15 & 0.29 & 0.74 & 0.75 & 0.59 \\
\hline & 37 & 75 & 8 & 0.16 & 0.50 & 0.41 & 0.35 \\
\hline & & & 15 & 0.07 & 0.49 & 0.40 & 0.32 \\
\hline & & 85 & 8 & 0.23 & 0.54 & 0.49 & 0.42 \\
\hline & & & 15 & 0.19 & 0.36 & 0.32 & 0.29 \\
\hline \multirow[t]{12}{*}{ LY6 } & 33 & 75 & 8 & 0.57 & 0.73 & 0.63 & 0.64 \\
\hline & & & 15 & 0.28 & 0.71 & 0.49 & 0.49 \\
\hline & & 85 & 8 & 0.68 & 0.86 & 0.74 & 0.76 \\
\hline & & & 15 & 0.50 & 0.82 & 0.71 & 0.68 \\
\hline & 35 & 75 & 8 & 0.35 & 0.48 & 0.48 & 0.44 \\
\hline & & & 15 & 0.27 & 0.45 & 0.42 & 0.38 \\
\hline & & 85 & 8 & 0.55 & 0.69 & 0.66 & 0.64 \\
\hline & & & 15 & 0.40 & 0.66 & 0.68 & 0.58 \\
\hline & 37 & 75 & 8 & 0.40 & 0.22 & 0.37 & 0.33 \\
\hline & & & 15 & 0.28 & 0.07 & 0.27 & 0.21 \\
\hline & & 85 & 8 & 0.52 & 0.33 & 0.43 & 0.43 \\
\hline & & & 15 & 0.35 & 0.34 & 0.42 & 0.37 \\
\hline \multirow[t]{12}{*}{ ZLY47 } & 33 & 75 & 8 & 0.63 & 0.66 & 0.49 & 0.60 \\
\hline & & & 15 & 0.49 & 0.63 & 0.38 & 0.50 \\
\hline & & 85 & 8 & 0.63 & 0.81 & 0.59 & 0.68 \\
\hline & & & 15 & 0.81 & 0.84 & 0.57 & 0.74 \\
\hline & 35 & 75 & 8 & 0.33 & 0.32 & 0.52 & 0.39 \\
\hline & & & 15 & 0.31 & 0.25 & 0.38 & 0.31 \\
\hline & & 85 & 8 & 0.37 & 0.65 & 0.53 & 0.52 \\
\hline & & & 15 & 0.40 & 0.53 & 0.47 & 0.47 \\
\hline & 37 & 75 & 8 & 0.25 & 0.31 & 0.50 & 0.35 \\
\hline & & & 15 & 0.08 & 0.22 & 0.40 & 0.24 \\
\hline & & 85 & 8 & 0.39 & 0.29 & 0.38 & 0.35 \\
\hline & & & 15 & 0.25 & 0.23 & 0.38 & 0.28 \\
\hline R168 & 33 & 75 & 8 & 0.50 & 0.96 & 0.98 & 0.81 \\
\hline
\end{tabular}




\begin{tabular}{|c|c|c|c|c|c|c|c|}
\hline & & & 15 & 0.41 & 0.88 & 0.89 & 0.73 \\
\hline & & \multirow[t]{2}{*}{85} & 8 & 0.43 & 0.92 & 0.95 & 0.77 \\
\hline & \multirow{3}{*}{35} & & 15 & 0.51 & 0.85 & 0.92 & 0.76 \\
\hline & & \multirow[t]{2}{*}{75} & 8 & 0.47 & 0.82 & 0.89 & 0.73 \\
\hline & & & 15 & 0.38 & 0.80 & 0.93 & 0.70 \\
\hline & \multirow{5}{*}{37} & \multirow[t]{2}{*}{85} & 8 & 0.63 & 0.96 & 0.96 & 0.85 \\
\hline & & & 15 & 0.41 & 0.85 & 0.92 & 0.73 \\
\hline & & \multirow[t]{2}{*}{75} & 8 & 0.55 & 0.67 & 0.68 & 0.63 \\
\hline & & & 15 & 0.18 & 0.53 & 0.71 & 0.47 \\
\hline & & \multirow[t]{2}{*}{85} & 8 & 0.44 & 0.73 & 0.75 & 0.64 \\
\hline & \multirow{5}{*}{33} & & 15 & 0.32 & 0.70 & 0.78 & 0.60 \\
\hline \multirow[t]{12}{*}{ IR64 } & & \multirow[t]{2}{*}{75} & 8 & 0.55 & 0.80 & 0.96 & 0.77 \\
\hline & & & 15 & 0.66 & 0.71 & 0.94 & 0.77 \\
\hline & & \multirow[t]{2}{*}{85} & 8 & 0.76 & 0.83 & 1.00 & 0.86 \\
\hline & & & 15 & 0.71 & 0.86 & 0.96 & 0.84 \\
\hline & \multirow[t]{4}{*}{35} & \multirow[t]{2}{*}{75} & 8 & 0.37 & 0.27 & 0.74 & 0.46 \\
\hline & & & 15 & 0.46 & 0.29 & 0.55 & 0.43 \\
\hline & & \multirow[t]{2}{*}{85} & 8 & 0.63 & 0.43 & 0.80 & 0.62 \\
\hline & & & 15 & 0.47 & 0.27 & 0.73 & 0.49 \\
\hline & \multirow[t]{4}{*}{37} & \multirow[t]{2}{*}{75} & 8 & 0.38 & 0.17 & 0.61 & 0.39 \\
\hline & & & 15 & 0.29 & 0.00 & 0.52 & 0.27 \\
\hline & & \multirow[t]{2}{*}{85} & 8 & 0.47 & 0.15 & 0.67 & 0.43 \\
\hline & & & 15 & 0.39 & 0.10 & 0.39 & 0.29 \\
\hline \multirow[t]{11}{*}{16343} & \multirow[t]{4}{*}{33} & \multirow[t]{2}{*}{75} & 8 & 0.72 & 0.97 & 0.76 & 0.82 \\
\hline & & & 15 & 0.51 & 1.00 & 0.61 & 0.71 \\
\hline & & \multirow[t]{2}{*}{85} & 8 & 0.82 & 0.85 & 0.78 & 0.82 \\
\hline & & & 15 & 0.68 & 0.98 & 0.77 & 0.81 \\
\hline & \multirow[t]{4}{*}{35} & \multirow[t]{2}{*}{75} & 8 & 0.19 & 0.25 & 0.39 & 0.28 \\
\hline & & & 15 & 0.09 & 0.26 & 0.21 & 0.19 \\
\hline & & \multirow[t]{2}{*}{85} & 8 & 0.44 & 0.43 & 0.65 & 0.51 \\
\hline & & & 15 & 0.43 & 0.33 & 0.32 & 0.36 \\
\hline & \multirow[t]{3}{*}{37} & \multirow[t]{2}{*}{75} & 8 & 0.06 & 0.28 & 0.11 & 0.15 \\
\hline & & & 15 & 0.00 & 0.19 & 0.05 & 0.08 \\
\hline & & 85 & 8 & 0.29 & 0.36 & 0.53 & 0.39 \\
\hline$\square$ & $\square$ & $\square$ & 15 & 0.26 & 0.27 & 0.00 & 0.18 \\
\hline
\end{tabular}

